\title{
LEMA AS A DIGITAL OBJECT MANIPULATION
}

\section{LEARNING ENVIRONMENT}

\author{
Ana Breda ${ }^{1}$, Eugénio Rocha ${ }^{2}$, Maria Isabel Santos ${ }^{3}$ \\ ${ }^{1,2}$ Department of Mathematics/CIDMA, University of Aveiro (PORTUGAL) \\ ${ }^{3}$ CIDMA, University of Aveiro (PORTUGAL)
}

\begin{abstract}
The Learning Environment on Mathematics for Autistic Children (LEMA) is a digital mathematical learning environment with modalities of dynamic adaptations of the proposed activities having in consideration the user's profile. Training Sessions with special teachers highlighted the need to add new technologies to LEMA. Following this line of thought it would be of great educational value the incorporation of a tabletop technology in LEMA. Among several major tabletop hardware, we have opted by the use of Kinects with a multi-touch tabletop system which can detect all the movements of the user making the human body as a remote control to assist the human computer interaction allowing the manipulation of simple objects connected with the scope of the embodied learning activities. In this paper, we will explain the several phases to the integration of this new technology in LEMA, giving special emphasis to the pedagogical framework underlying the adaptations of the incorporated math activities.
\end{abstract}

Keywords: Autism spectrum disorder, tabletop interfaces, 3D object manipulation, math skills.

\section{INTRODUCTION}

GEOMETRIX, a strand line of CIDMA (Center for research and Development in Mathematics and Applications), is a research and development line, interdisciplinary-oriented, targeted at assorted target groups (running from primary to higher education level), committed to the study, use and creation of intelligent digital environments to promote knowledge and skills in mathematics, reflecting a transformation in the way they are grasped and applied. Under this scope it was developed the prototype LEMA, a digital Learning Environment on Mathematics for Autistic children, with modalities of dynamic adaptation of the proposed activities, able to promote knowledge and skills in mathematics in children, aged between 6 and 12 years, diagnosed with Autism Spectrum Disorders (ASD).

Besides the core difficulties associated with children with ASD (communication and social interaction, and, repetitive patterns of behavior, interests or activities), that can compromise their personal and social autonomy in various contexts, these children may also experience few sensory tolerance and may have limited motor ability [1].

The use of Digital Technologies can be an effective way to create innovative learning opportunities to these children and to develop creative, personalized and constructive environments, where they can develop differentiated skills [2]. These children often respond well to learning activities involving information presented visually. Digital environments present opportunities for dynamic customizable visual displays, which can be used to individualize instruction by selecting, for instance, appropriate difficulty levels according to a particular student's ability level [3], [4].

The prototype LEMA has already been evaluated with end-users and based on the analysis of the collected data the respective readjustments were made. In the training sessions with special teachers the need to add new technologies to LEMA raised. In fact, for those who have poor motor coordination, the tabletop technology is a good answer bringing real advantages because it allows unmediated control over the objects with which the user is interacting with. Among several major tabletop hardware we have opted by the use of Kinects with a multi-touch tabletop system which can detect all the movements and gestures of the user and transfer them to the computer [5], [6]. The reason to choose this option is described below.

Kinect technology has potential in training different skills in children with ASD, among others it enables children with ASD to work in teams, facilitating the cooperation between children, promoting a 
gradually development of their oral expression, coming to a point where they can give basic instructions to each other. The activities incorporated in the digital environment follow a repetitive pattern making the end-users gradually more and more familiar with the learning data, ideas and tools, increasing their feeling of self-esteem, self-understanding, autonomy and independence [7]. Additionally, the Kinects may be used for rehabbing balance, motor skills, increasing autonomy and citizenship inside and outside school situations.

Summarizing, the incorporation of Kinect technology increases learning outcomes and motivation for learning, ensuring a longer attention span in the learning activities [6], [7].

In this paper, we will explain the several developmental phases for the integration of Kinects in LEMA, giving special emphasis to the pedagogical framework underlying the adaptations that must be done for the already incorporated math activities. Some guidelines for future work will be also given.

\section{METHODOLOGY}

The methodological options of this proposal are framed by prototyping and development techniques combined with the analysis of a set of case studies with children with ASD, using the digital environment under development. Given its exploratory nature, this research follows a process of successive refinements and prototype developments, starting from a theoretical basis which will be enriched by a qualitative analysis of requirements resultant of the prototype exploration sessions that will be running over time, as proposed by Richey and Klein [8].

This approach requires that end users and other stakeholders are involved in all stages of the development process, providing their insights about the required features to the product and testing different design solutions. This is a delicate aspect of this project, as the target users are children with special needs. Hence, we took special care with regard to the ethical aspects of this work.

The pedagogical framework underlying of the incorporated math activities in the LEMA will strongly follow the four principles of therapeutic and educational intervention of Cain and Seeman cited by [6], Namely, LEMA will has:

- Repetitive exercises;

- Personalized flow of learning activities;

- Combination of visual, auditory, and kinesiology stimuli;

- Step-wise activities with frequent feedback and reinforcement.

\section{PHASES OF EMPIRICAL WORK}

LEMA integrates modalities of dynamic adaptation of the activities proposed to the user. These activities are designed to promote the development of mathematical reasoning, having in account a preliminary study carried out with children aged between 6 and 12 years diagnosed with ASD [9]. The functional profiles of the selected students for this study have played, as naturally expected, a fundamental role in the design of these activities.

Our proposal to design LEMA math activities has focused on the following geometric topics: bidimensional geometric shapes, perimeters and areas of planar figures and planar isometries. In these activities, the skills to be worked on are: mathematical communication, mathematization, (distinct) representation of geometric shapes, mathematical reasoning involving geometric and visual thinking, elaboration of strategies for problem solving, use of language and symbolic operations and use of mathematical tools [10].

The technical implementation of LEMA is assured by a multidisciplinary team (mathematicians, educators, developers and designers) currently affiliated to the Thematic Line Geometrix (http:// geometrix.web.ua.pt) of the Centre for Research and Development in Mathematics and Applications (CIDMA), located in the Department of Mathematics at the University of Aveiro (Portugal).

In a certain way, the sensory tolerance and motor ability levels have been neglected in the design and implementation of the first two LEMA's versions. LEMA has the mouse and the keyboard as main interaction devices, which do not help children in improving gross or fine motor skills and are often inappropriate for children with hyperactivity as can be the case of the children with ASD. 
We have pointed out crucial reasons why Kinects must be incorporated in LEMA. They will be of great help for children with ASD with motor difficulties besides they may be used for the improvement of eye-hand coordination, visual perception, motor planning and execution skills, cultivating, simultaneously, mental capabilities reaching planned levels of school performance according to the indicators of their cognitive abilities, gaining experience through interactive learning games [6].

\subsection{Design LEMA's interface and learning activities}

As children with ASD may face barriers in understanding information and decoding language, the recommended ways to design the interface are: the use of simple, visual and textual language; the avoidance of jargon, spelling errors, metaphors and acronyms; the use of terms, expressions, names and symbols familiar to the users' context [11]; the avoidance of writing long paragraphs; the use of mark-ups that facilitate the reading flow such as lists and heading titles and icons. The use of images and menu label's actions compatible with the real world, representing concrete actions and everyday life activities in order to be easily recognized [12], [13].

All activities were conceived within a minimalism thought, with few items on the screen, clear interface with contrasting colours, without distracters or background images, making use of large buttons and icons.

Regarding the first and second principles of Cain and Seeman's therapeutic and educational intervention, LEMA enables users to repeat embedded activities whenever they want and provides the personalized selection of ten activities taking into account the functional profile of the user with ASD and his mathematical capability.

Several authors underline the importance of the use of feedbacks for children with ASD to guide them to perform tasks [13]-[15]. In agreement with the third and fourth principles of the abovementioned authors, LEMA provides information in multiple representations, such as text, video, audio and image, providing clear task instructions and orientations to ease the user understanding of the content and content language. This approach stimulates, motivates and engages the users during their interaction with LEMA's activities. For the reasons above mentioned and aiming the promotion of an efficient communication between the system and the user, LEMA provides frequent informative, learning content and reinforcement feedback.

\subsection{Object manipulation in the learning environment LEMA}

The manipulations of the virtual objects will be done using Microsoft Kinect for Windows device, so instead using the mouse, the children will interact with objects with their own hands, improving their motor capabilities. The basic gestures are the closed hand, for grabbing and dragging an object, and the simple click, for selecting an object or clicking a button, that is done by slightly moving an open hand in the direction of the Kinect.

The set up requires the Kinect device to be placed in front of the user attached to a laptop or desktop running the application, which can be connected to a TV screen or projector placed in front of the user, above the Kinect device.

We also planned the incorporation of real objects manipulation which will be placed on the top of a table being identified by a webcam above it and mapped to the corresponding virtual objects in the projection, allowing also the manipulation of the virtual objects with corresponding real ones.
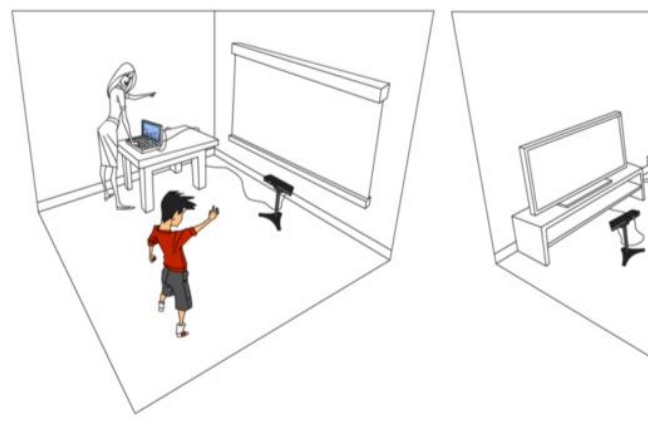

Figure 1: Set up for execution the Kinect LEMA's learning activities 


\section{CONCLUSIONS}

The next step in this research project will be the validation of the incorporation of Kinects in LEMA. The validation will be supported by a plan with regular sessions with end-users and training session with their teachers.

We hope that the digital environment that is being developed may prove to be a learning tool able to offer learning activities dynamically adapted to the individual needs of students with autism, ensuring access and equity to the process of teaching and learning, being also a powerful tool to support teachers and educators. Moreover, It is expected that LEMA will foster new opportunities and educational strategies and improve math skills in students with ASD, thus preparing their transition to a more active, autonomous and inclusive life.

\section{ACKNOWLEDGEMENTS}

This work was supported in part by Portuguese funds through the CIDMA - Center for Research and Development in Mathematics and Applications, and the Portuguese Foundation for Science and Technology ("FCT - Fundação para a Ciência e a Tecnologia"), within project UID/MAT/04106/2013. M. I. Santos also acknowledges the support of FCT through the Research Grant SFRH/BD/108154/2015

\section{REFERENCES}

[1] American Psychiatric Association, Diagnostic and Statistical Manual of Mental Disorders. American Psychiatric Association, 2013.

[2] C. E. Burton, D. H. Anderson, M. A. Prater, and T. T. Dyches, "Video self-modeling on an iPad to teach functional math skills to adolescents with autism and intellectual disability," Focus Autism Other Dev. Disabl., vol. 28, no. 2, pp. 67-77, 2013.

[3] V. Knight, B. R. McKissick, and A. Saunders, "A review of technology-based interventions to teach academic skills to students with autism spectrum disorder.," J. Autism Dev. Disord., vol. 43, no. 11, pp. 2628-48, Nov. 2013.

[4] S. Ramdoss, A. Mulloy, R. Lang, M. O'Reilly, J. Sigafoos, G. Lancioni, R. Didden, and F. El Zein, "Use of computer-based interventions to improve literacy skills in students with autism spectrum disorders: A systematic review," Res. Autism Spectr. Disord., vol. 5, no. 4, pp. 13061318, Oct. 2011.

[5] W. Chen, "Multitouch Tabletop Technology for People with Autism Spectrum Disorder: A Review of the Literature," Procedia Comput. Sci., vol. 14, no. 1877, pp. 198-207, Jan. 2012.

[6] G. Altanis, M. Boloudakis, S. Retalis, and N. Nikou, "Children with Motor Impairments Play a Kinect Learning Game: First Findings from a Pilot Case in an Authentic Classroom Environment," Interact. Des. Archit. J. - IxD\&A, no. 19, pp. 91-104, 2013.

[7] E. Boutsika, "Kinect in education: A proposal for children with autism," Procedia Comput. Sci., vol. 27, no. Dsai 2013, pp. 123-129, 2013.

[8] R. . Richey and J. D. Klein, "Developmental research methods: Creating knowledge from instructional design and development practice," Journal of Computing in Higher Education, vol. 16, no. 2. pp. 23-38, 2005.

[9] M. I. Santos, A. Breda, and A. M. Almeida, "Brief Report: Preliminary Proposal of a Conceptual Model of a Digital Environment for Developing Mathematical Reasoning in Students with Autism Spectrum Disorders," J. Autism Dev. Disord., vol. 45, no. 8, pp. 2633-2640, Aug. 2015.

[10] M. I. Santos, A. Breda, and A. M. Almeida, "Design approach of mathematics learning activities in a digital environment for children with autism spectrum disorders," Educ. Technol. Res. Dev., pp. 1-19, Apr. 2017.

[11] A. Darejeh and D. Singh, "A review on user interface design principles to increase software usability for users with less computer literacy," J. Comput. Sci., vol. 9, no. 11, pp. 1443-1450, 2013. 
[12] F.-K. Lau, A. H. K. Yuen, and J. M.-G. Lian, "Adapted design of multimedia-facilitated language learning program for children with autism," Psicol. Esc. e Educ., vol. 11, no. spe, pp. 13-26, 2007.

[13] R. Muñoz, T. Barcelos, Noe, R. L, and S. Kreisel, "Development of software that supports the improvement of the empathy in children with autism spectrum disorder," Proc. - Int. Conf. Chil. Comput. Sci. Soc. SCCC, pp. 223-228, 2013.

[14] L. C. S. Greis and A. B. Raposo, "Metáforas de Perspectivas Culturais na (re) definição de padrões de colaboração de um jogo de multi-toque para usuários com autismo," vol. 5138, pp. 112-121, 2013.

[15] K. Sitdhisanguan, N. Chotikakamthorn, A. Dechaboon, and P. Out, "Using tangible user interfaces in computer-based training systems for low-functioning autistic children," Pers. Ubiquitous Comput., vol. 16, no. 2, pp. 143-155, May 2011. 